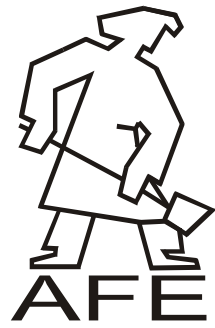

\title{
The Mechanical Properties of AlSi17Cu5 Cast Alloy after Overheating and Modification of CuP Master Alloy
}

\author{
J. Piątkowski ${ }^{\text {a, *, M. Jabłońska }}{ }^{\text {b }}$ \\ ${ }^{a}$ Department of Materials Technology, ${ }^{b}$ Department of Materials Science \\ Silesian University of Technology, Krasińskiego 8, 40-019 Katowice, Poland \\ *Corresponding author. E-mail address: jaroslaw.piatkowski@polsl.pl
}

Received 09.04.2013; accepted in revised form 27.05.2013

\begin{abstract}
The paper presents the results of studies on the effect of the AlSi17Cu5 alloy overheating to atemperature of $920^{\circ} \mathrm{C}$ and modification with phosphorus (CuP10) on the resultingmechanical ( $\left.\mathrm{HB}, \mathrm{R}_{\mathrm{m}}, \mathrm{R}_{0.2}\right)$ and plastic $\left(\mathrm{A}_{5}\right.$ and $\left.\mathrm{Z}\right)$ properties. It has been shown that, so-called, "timethermal treatment" (TTT) of an alloy in the liquid state, consisting inoverheating the metal to about $250^{\circ} \mathrm{C}$ above $\mathrm{T}_{\text {liq }}$,holding at this temperature by 30 minutes improvesthe mechanical properties. It has also been found that overheating of alloy above $\mathrm{T}_{\text {liq. }}$ enhances the process of modification, resulting in the formation of fine-grain structure. The primary silicon crystals uniformly distributed in the eutectic and characteristics ofthe $\alpha(\mathrm{Al})$ solution supersaturated with alloying elements present in the starting alloy composition $(\mathrm{Cu}, \mathrm{Fe})$ provide not only an increase of strength at ambient temperature but also at elevated temperature $\left(250^{\circ} \mathrm{C}\right)$.
\end{abstract}

Keywords: Hypereutectic Al-Si alloys, Overheating, Modification with CuP10 master alloy, Mechanical and plastic properties

\section{Introduction}

As a result of the solidification process, hypereutectic Al-Si alloys developthestructurecomposed ofasoftdendritic Al matrix with large primary silicon crystals of a non-uniform distribution. A structure of this type has very disadvantageous effect on the mechanical properties and machinability of castings, and therefore the key issue in the application of Al-Si alloys is to reduce the size of primary Si crystals and ensure their uniform distribution. This goal can be achieved through for example modification and refining [1-5] of cast alloys, and also through overheating of melt before casting [6-9].

The results of recent studiessuggest that superheating of liquid alloyabove the $\mathrm{T}_{\text {liq. }}$, holding at that temperatureand cooling can alsocause the refinement of primarysilicon crystals and their uniform distribution of the $\alpha-\beta$ eutectic [10-14].

\section{Scope and purpose of research}

The aim of the study is to demonstrate what impact the overheating degree and modification process (considered separately orjointly) can have on the change in mechanical (HB, $\left.\mathrm{R}_{\mathrm{m}}, \mathrm{R}_{0.2}\right)$ and plastic $\left(\mathrm{A}_{5}, \mathrm{Z}\right)$ properties of the casting AlSi17Cu5 cast alloy.

To achieve this aim, the scope of work includes:

- choice of alloy and development of a technological conceptof its modificationthrough strong overheating,

- overheating the liquid alloy to a temperature of $920^{\circ} \mathrm{C}$, holding at this temperature for $30 \div 40$ minutes in the furnace and casting to a metal mould,

- $\quad$ measurement of mechanical properties $\left(\mathrm{HB}, \mathrm{R}_{\mathrm{m}}, \mathrm{R}_{0.2}\right)$,

- measurement of plastic properties $\left(\mathrm{A}_{5}\right.$ and $\left.\mathrm{Z}\right)$ - at ambient temperature $\left(20^{\circ} \mathrm{C}\right)$ and at elevated temperature $\left(250^{\circ} \mathrm{C}\right)$,

- $\quad$ study of microstructure. 


\section{Research method and materials}

Casting of specimens for testing of mechanical and plastic properties was carried out in the chamber of a Balzers VSG 02/631 vacuum induction furnace.Alloys were melted in an $\mathrm{SiC}$ crucible of $800 \mathrm{~cm}^{3}$ capacityand cast into a steel mould producing simultaneously three $\varnothing 200 \times 1600 \mathrm{~mm}$ specimens, which were next machined to the dimensions complying with PN EN10002-1. To avoid the negative impact of various phenomena related with the presence of gas in liquid metal bath, resulting from the highdegree overheating of alloy above the $\mathrm{T}_{\text {liq }}$ point, a ProtecolDegasal protective coating was applied. The mixture $(0.4 \mathrm{wt} . \%)$ was introduced by immersion under the surface of the molten metal bath, and under the layer of produced slag, $0.2 \mathrm{wt} . \%$ of the Rafglin-3 alloy refiner was added. Then the alloy was overheated at $920^{\circ} \mathrm{C}$ for $30 \div 40$ minutes. With the working chamber of the furnace kept closed, $0.05 \mathrm{wt} . \%$ of $\mathrm{P}$ in the form of a CuP10 master alloy was added, and after 10 minutes, the bath was deslagged and the alloy was cast to an steel mould in four different conditions:

1. Unmodified (designated by the symbol SN),

2. Modified with 0.05 wt.\% P in the form of a CuP10 master alloy (designated by the symbol SM),

3. Overheated at $920^{\circ} \mathrm{C}$ for $30 \div 40$ minutes in the furnace (designated by the symbol SP),

4. Overheated and modified according to the parameters as stated above (designated by the symbol SPM).

Brinell hardness test was performed in accordance with PN-EN ISO 6506-1 on a Zwick ZHF hardness tester under a load of 187.5 $\mathrm{kg}$ using a $2.5 \mathrm{~mm}$ diameter steel ball applied for a time of 35 seconds. Static tensile test at room temperature $\left(20^{\circ} \mathrm{C}\right)$ was carried out in accordance with PN EN ISO 6892-1 on a 3382 Instron machine, using a 20:1 ratio and a constant tensile speed of 5 $\mathrm{mm} / \mathrm{min}$. The following parameters were determined: tensile strength $\left(\mathrm{R}_{\mathrm{m}}\right)$, yield strength $\left(\mathrm{R}_{0.2}\right)$, elongation $\left(\mathrm{A}_{5}\right)$, and reduction of area after specimen fracture (Z). Applying the same parameters, the mechanical tests were carried out at a temperature of $250^{\circ} \mathrm{C}$, selected as a value reflecting the actual operating conditions of AlSi17Cu5 alloy. Twelve measurements were taken, discarding the two extreme values, and calculating an arithmetic mean from the remaining values.

\section{The results of investigations}

\subsection{Mechanical properties}

Tests were carried out on an AlSi17Cu5 alloy whose chemical composition is given in Table 1.

Table 1.

Chemical analysis of the examined castalloy (wt.\%)

\begin{tabular}{cccccccc}
\hline \multirow{2}{*}{ Alloy } & \multicolumn{7}{c}{ Chemical composition of $\mathrm{AlSi} 17 \mathrm{Cu} 5$ alloy } \\
\cline { 2 - 8 } & $\mathrm{Si}$ & $\mathrm{Cu}$ & $\mathrm{Fe}$ & $\mathrm{Mn}$ & $\mathrm{Mg}$ & $\mathrm{Ni}$ & $\mathrm{Al}$ \\
\hline $\begin{array}{c}\text { AlSi17 } \\
\text { Cu5 }\end{array}$ & 16,81 & 0,17 & 0,54 & 0,03 & 0,04 & 0,13 & rest \\
\hline
\end{tabular}

The results of Brinell hardness measurements obtained for the aforementioned four technological variantsisshown in Figure 1a. The results of static tensile test to determine the tensile strength $\mathrm{R}_{\mathrm{m}}$ of AlSi17Cu5 cast alloy at ambient temperature and at elevated temperature $\left(250^{\circ} \mathrm{C}\right)$ are shown in Figure $1 \mathrm{~b}$; Figure $1 \mathrm{c}$ shows the same results obtained for the yield strength.

Average values of the reduction of area after specimen fracture $(\mathrm{Z})$ and of elongation $\left(\mathrm{A}_{5}\right)$, plotted in function of the technological variant selected, are shown in Figures $2 a$ and $2 b$, respectively.

a)

ambienttemperature

elevatedtemperature

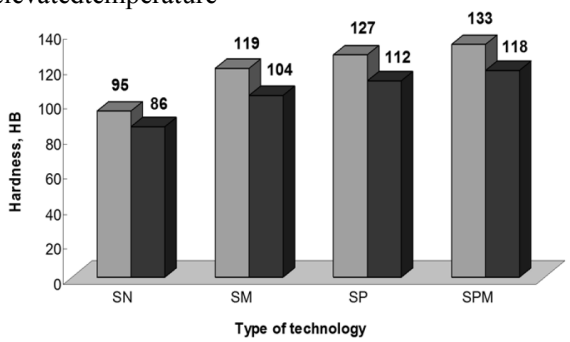

b)

ambienttemperature

elevatedtemperature

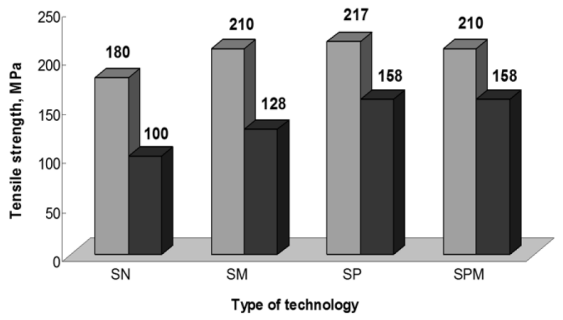

c)

ambienttemperature

elevatedtemperature

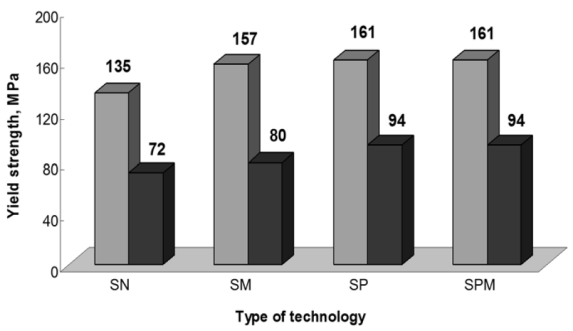

Fig. 1. Mechanical properties of AlSi17Cu5 cast alloy at ambient temperature $\left(20^{\circ} \mathrm{C}\right)$ and at elevated temperature $\left(250^{\circ} \mathrm{C}\right)$ :

a) Brinell hardness, b) the tensile strength $\left.R_{m}, c\right)$ the yield strength $R_{0.2}$ by four variants of the technology 
a)

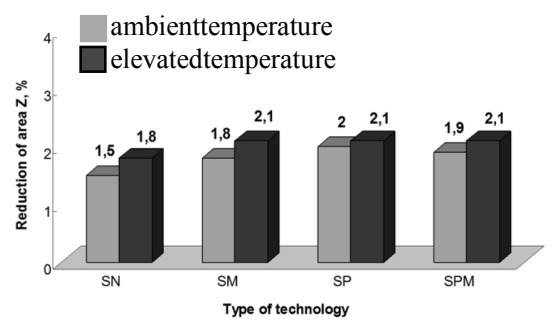

b)

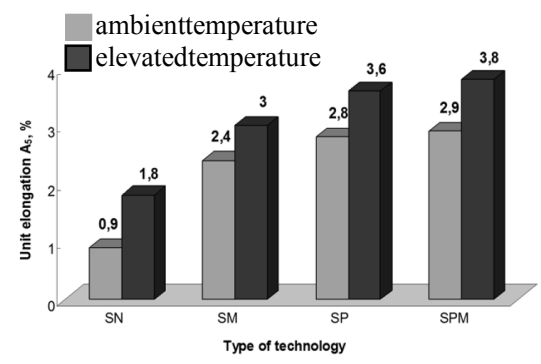

Fig. 2. Plastic properties of AlSi17Cu5 cast alloy at ambient temperature $\left(20^{\circ} \mathrm{C}\right)$ and at elevated temperature $\left(250^{\circ} \mathrm{C}\right)$ :

a) reduction of area $Z, b$ ) the unit elongation $A_{5}$ by four variants of the technology

\subsection{Study of microstructure}

A complementary research to the solidification process was study of microstructure. Microstructures of AlSi17Cu5 alloy unmodified and modified with $0.05 \mathrm{wt} . \% \mathrm{P}$ in the form of a $\mathrm{CuP} 10$ master alloy are shown in Figure 3. Microstructures of AlSi17Cu5 alloy overheated to $920^{\circ} \mathrm{C}$ and overheated to $920^{\circ} \mathrm{C}$ and modified with 0.05 wt.\% phosphorus is shown in Figure 4.

a)

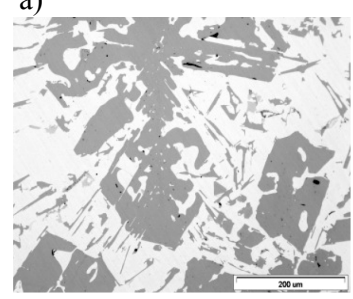

b)

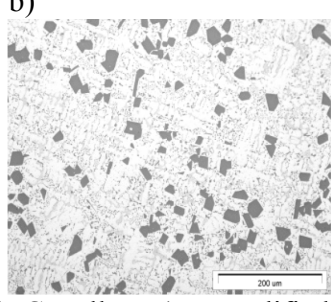

i17Cu5alloy: a) unmodified b) modified with $0.05 \mathrm{wt} . \%$ phosphorus (CuP10)

a)
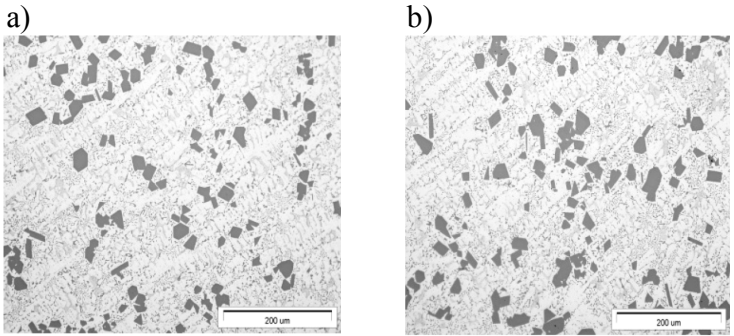

Fig. 4. Microstructure ofAlSi17Cu5 alloy: a) overheated to $\left.920^{\circ} \mathrm{C}, \mathrm{b}\right)$ overheated to $920^{\circ} \mathrm{C}$ and modified with $0.05 \mathrm{wt} . \%$ phosphorus (CuP10 master alloy)

\section{Summary of the results}

As follows from the studies, each time the application of:

$\checkmark$ modification with 0.05 wt.\% P (CuP10)-SM,

$\checkmark$ overheating for $30 \div 40 \mathrm{~min}$. to a temperature of $920^{\circ} \mathrm{C}-\mathrm{SP}$,

$\checkmark \quad$ overheating and modification-SPM.

increased the alloy hardness HB by $21 \%$ respectively, while the combined process of strong overheating and modification resulted in a $29 \%$ increase as compared to the AlSi17Cu5 alloy in an unmodified condition (SN).

So it can be concluded that alloy overheatingabove $T_{\text {liq. }}$ produces similar effects of hardness increase as the process of modification or modificationcombined with strong overheating. This is related with the degree of under cooling, the value of which may reach even $106 \mathrm{~K} \cdot \mathrm{s}^{-1}$, corresponding to the phase growth rate of approximately $200 \mathrm{~m} \cdot \mathrm{s}^{-1}$ [15]. Pouring the alloy into a steel mould speeds up the solidification process, and is one of the casting techniques used to produce metastable and amorphous alloys. Additionally, rapid heat transferrefinesalloy structure,raisingthe number of potential substrates for heterogeneous nucleation of silicon. Another advantage of rapid solidification is the possibility to produce a more homogeneous melt, owing to the reduced heterogeneity of chemical composition and increased solubility limit of alloying elements in the solid phase. This can explain, among others,the increase ofmechanical properties as compared to the properties of alloys castby conventional techniques.

The remaining part of studiesconcerningthe effect of technological process on the mechanical and plastic properties of the investigated alloymainly focussed on the results of static tensile test. Since alloys tested for automotive applications are usually cast into metal moulds, a die was used in these testsand in this die, twelve samples were cast using each of the four technological variantsdeveloped. The obtained values of the tensile strength $\left(\mathrm{R}_{\mathrm{m}}\right)$ and yield strength $\left(\mathrm{R}_{0.2}\right)$ were analysed and showedin each case an increase in the properties of the examined material as compared to the alloy in basecondition-see Figures $1 \mathrm{~b}$ and $1 \mathrm{c}$, respectively. Modification with phosphorusorstrong overheating of the alloy increasedthe tensile strength by $16 \div 18 \%$ compared tothe alloy in basecondition, i.e. unmodified and without overheating, while the combined process of overheating and modification with phosphorus increased this property by $28 \%$ (at ambient temperature).

Modification or overheating above $\mathrm{T}_{\text {liq. }}$ as well as a combination of these two methods finally gave $\mathrm{R}_{0.2}=161 \mathrm{MPa}$, which meansabout $20 \%$ increase (at ambient temperature) compared to the alloy unmodified and without overheating.

Compared to the unmodified condition, the applied technological variants also changed the alloyplastic properties. All variantsgave the reduction of area after fracture $\mathrm{Z}=2 \%$ and elongation $\mathrm{A}_{5}=3 \%$, which means a considerable improvement of plastic properties in respect ofthe alloy in base condition - see Figures $2 a$ and $2 b$, respectively.

As mentioned previously, practical application of the examined alloy mainly focussed on cast pistons and heads of IC engines. Typically, the piston crown holds an appropriately shaped combustion chamber, in which nearly all of the heat supplied together with the fuelis evolved. These conditions increase the thermal load under which the piston is operating, making it, 
in some extreme cases, heated to a temperature of $310^{\circ} \mathrm{C}$, with a change of $12^{\circ} \mathrm{C}$ in one operating cycle. On this information were basedthe mechanical tests carried out at elevated temperature. From Figure 1 bit follows that at this temperature,the tensile strength $R_{m}$ suffers a drop of $55 \%$ when the alloy is not modified. Hence, it can be concluded that modification (or any other treatment that refines the alloy structure) is necessary, particularly when the Al-Si-Me alloys are used for parts operating at elevated temperatures (in the engine working chamber). Due to the developed technological variants of alloy treatment, the drop of $\mathrm{R}_{\mathrm{m}}$ at the temperature of $250^{\circ} \mathrm{C}$ was less sharp and amounted to:

- $40 \%$ for alloy modified with phosphorus (SM),

- $28 \%$ for alloy overheated to a temperature of $920^{\circ} \mathrm{C}$ (SP),

- $25 \%$ for alloy overheated and modified (SPM).

From the above it follows that after the process of strong overheating of the AlSi17Cu5 alloy above $\mathrm{T}_{\text {liq. }}$ the tensile strength $\mathrm{R}_{\mathrm{m}}$ at atemperature of $250^{\circ} \mathrm{C}$ will drop from $210 \mathrm{MPa}$ (at ambient temperature) to $128 \mathrm{MPa}$ after the modification with phosphorus and to $158 \mathrm{MPa}$ after strong overheating. Data on the mechanical and thermal loads under which pistons are operating show that piston crown must withstand the stresses of approximately 80 $\mathrm{MPa}$ at the moment of the maximum load application. Current trends in designing of pistonsfor engines of the new generation are rather focussed on reduction of the overall piston height by about $20 \div 40 \%$ to increase the engine power and improve fuel efficiency. This change causes further increase in both mechanical and thermal loads up to even $120 \mathrm{MPa}$. The results shown in Figures 1 and 2 indicate that each of the technological variants applied meets this criterion.

Studies of the yield strength $\mathrm{R}_{0.2}$ at elevated temperatures showed a decrease of this parameter by:

- $47 \%$ for alloy in base condition (from 135 to $72 \mathrm{MPa}$ ),

- $49 \%$ for alloy after modification with $\mathrm{P}($ from 157 to $80 \mathrm{MPa})$,

- $42 \%$ for alloy overheated to a temperature of $920^{\circ} \mathrm{C}$ (from 161 to $94 \mathrm{MPa}$ ),

- $42 \%$ for alloy overheated and modified according to the parameters as stated above (from 161 to $94 \mathrm{MPa}$ ).

These data indicate that overheating the alloy to a temperature of $920^{\circ} \mathrm{C}$ and holding at this temperature for $30 \div 40$ minutes (SP) as well asa combined process of overheating and modification with phosphorus (SPM) result in the smallest drop of the yield strength $\mathrm{R}_{0.2}$ at elevated temperatures $(42 \%)$. At $250^{\circ} \mathrm{C}$, the yield strength $R_{0.2}$ suffers the most severe drop of $49 \%$ in alloy subjected to the sole process of modification with phosphorus and of $47 \%$ in alloy in the base condition (SW), compared with the results obtained at ambient temperature. On the other hand, a growing tendency has been observed in the reduction of area and unit elongation after fracture.

The final conclusion is that the increase of mechanical $\left(H B, R_{0.2}\right.$, $\mathrm{R}_{\mathrm{m}}$ ) and plastic $\left(\mathrm{Z}, \mathrm{A}_{5}\right)$ properties is the result of a modification with phosphorus and strong overheating above $T_{\text {liq. }}$ with subsequent rapid cooling. This is consistent with the assumptions made in the thesis of this study about the manufacture of light hypereutectic Al-Si-Me alloys subjected in the liquid state to a time-thermal treatment conferring to them in as-cast state the required high mechanical properties, combined with the satisfactory plastic properties. This favourable relationship of material characteristics is expected to contribute to the fact that in some applications, the cast hypereutectic Al-Si-Me alloys will gain an advantage over their hypoeutectic and wrought counterparts.

The results of the studies of mechanical and plastic properties were confirmed with microstructure examinations. In the unmodified AlSi17Cu5 cast alloy the crystals of silicon assumed a large, star-like shape (Fig. 3a). Modification with phosphorus $(\mathrm{CuP})$ causes fragmentation of the microstructure - Figure $3 \mathrm{~b}$.

Overheating to $920^{\circ} \mathrm{C}$ temperature (Fig. 4a), causes high degree of structure refinement was observed. Silicon crystals reduced their size, became more compact and more evenly distributed in the matrix of $\alpha(\mathrm{Al})-\beta(\mathrm{Si})$ eutectic.

\section{Acknowledgements}

FinancialsupportofStructuralFundsintheOperationalProgrammeInnovative Economy (IE OP) financed from the European Regional Development Fund - Project POIG.01.01.02-00-015/09.

\section{References}

[1] Xu, C.L. \& Wang, H.Y. (2007). Materials Science and Engineering. 341. 452-453.

[2] Shi, W. \& Gao, B. (2010). Journal. of Rare Earths. 28, 367.

[3] Lu, D.H., et al. (2007). Journal of Materials Processing Technology. 189, 13.

[4] Lashkari, O. \& Ajersch, F. (2008). Materials Science and Engineering. 428, 377.

[5] Xu, C.L. et al. (2006). Materials Science and Engineering. $\mathrm{A}(417), 275$.

[6] Zuo, M., et al. (2009). J Journal of Materials Processing Technology. 209, 5504.

[7] Makhlouf, M.M. \& Guthy, H.V. (2001). Journal of Light Metals. 1, 199.

[8] Lashkari, O. \& Ajersch, F. (2008). Materials Science and Engineering. 377.

[9] Pei, Y.T. \& De Hosson, J.T.M. (2001). Acta Materialia. 49, 561.

[10] Piątkowski, J., Gajdzik, B. \& Matuła, T. (2012). Metalurgija 51(3), 321.

[11] Piątkowski, J. (2012). Solid State Phenomena.191, 23.

[12] Piątkowski, J. (2010). Archives of Foundry Engineering 10(2), 135.

[13] Piątkowski, J. (2011). Solid State Phenomena.176, 29.

[14] Piątkowski, J. (2013). Monograph. Katowice: Silesian University of Technology.

[15] Kurz, W. \& Fisher, D.J. (1986). Fundamentals of Solidification, Trans. Tech. Publ. 